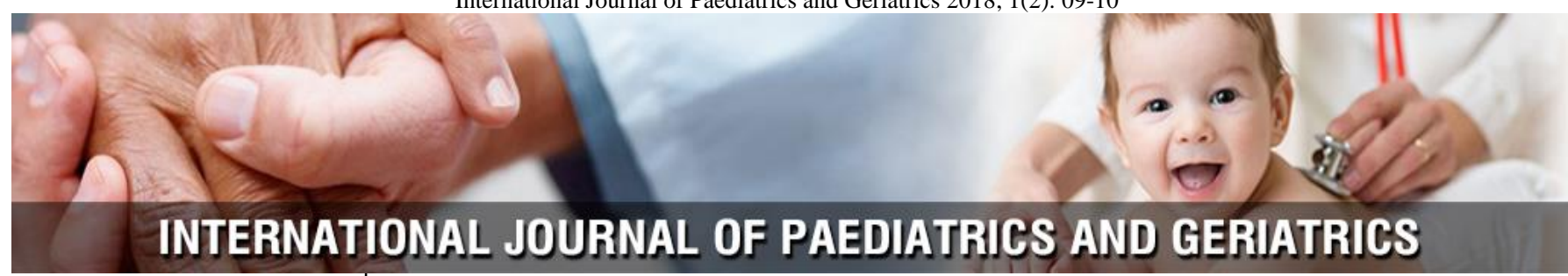

P-ISSN: 2664-3685

E-ISSN: $2664-3693$

www.paediatricjournal.com

IJPG 2018; 1(2): 09-10

Received: 13-05-2018

Accepted: 15-06-2018

Dr. Vicky Choudhury

Adesh Medical College \&

Hospital, Mohri, Haryana,

India

\section{Pattern of injuries in epileptic children: A clinical study}

\author{
Dr. Vicky Choudhury
}

DOI: https://doi.org/10.33545/26643685.2018.v1.i2a.12

\begin{abstract}
Background: The Epilepsies are chronic neurological disorders characterized by a predisposition for recurrent epileptic seizures. The present study was conducted to assess pattern of injuries epileptic children.

Materials \& Methods: The present study was conducted on 78 cases of epilepsy of both genders. Parents of children with epilepsy were interviewed with a semi-structured questionnaire. Other factors such as seizure types, duration, frequencies, and injuries were recorded.

Results: Out of 78 patients, boys were 48 and girls were 40. Common type of seizures was tonic clonic in 52 , absence in 12 , myoclonic in 6 , focal with impaired consciousness in 4 and unclassified in 4 . The difference was significant $(P<0.05)$.

Conclusion: Authors found that common type of injuries in epileptic children were soft tissue and abrasions.
\end{abstract}

Keywords: Children, epileptic, myoclonic.

\section{Introduction}

Epilepsy is defined as the repeated occurrence of unprovoked epileptic seizures. The most common type of epileptic seizure occurring in childhood, however, is the febrile seizure. Febrile seizures are occasional seizures provoked by an elevation of body temperature; they do not indicate the presence of epilepsy, even if they occur repeatedly ${ }^{[1]}$.

The Epilepsies are chronic neurological disorders characterized by a predisposition for recurrent epileptic seizures; the heterogeneity of the entities in this group is obvious today. The pharmacological choices (need for treatment, type of drug), duration of treatment, the non-pharmacological approach (epilepsy surgery, ketogenic diet) and other general recommendations

Depend on the type of epileptic syndrome and on the etiology of epilepsy. Correct diagnosis has practical consequences: optimal therapeutic choice and appreciation of the epilepsy outcome $^{[2]}$.

Neonatal seizures are never generalized, due to the incomplete myelination and inability to produce synchrony. They often appear fragmentary or multifocal, and may be "subtle", but apnea Alone is rarely a seizure. Synchronous motor events usually reflect brainstem activity with severe injuries. Pre and perinatal injury and metabolic causes are most common. Neonatal ictal behaviors usually change within a few months ${ }^{[3]}$.

EEG when abnormal can suggest the nature of the seizure tendency as focal or generalized, but does not determine whether or not a spell was a seizure or whether or not to treat, therefore help in drug selection, the value of a scan, and the prognosis. $50 \%$ of patients with partial seizures show focal spikes (or slowing), up to $75 \%$ after repeat studies or sleep deprivation ${ }^{[4]}$.The present study was conducted to assess pattern of injuries epileptic children.

\section{Materials \& Methods}

The present study was conducted in the department of pediatrics. It comprised of 78 cases of epilepsy of both genders. The study protocol was approved from institutional ethical committee and written consent was obtained from parents of all children.

Data related to children such as name, age, gender etc. was recorded. Parents of children with epilepsy were interviewed with a semi-structured questionnaire. Other factors such as seizure types, duration, frequencies, and injuries were recorded. Results were tabulated and subjected to statistical analysis. $\mathrm{P}$ valve less than 0.05 as considered significant.
Corresponding Author: Dr. Vicky Choudhury Adesh Medical College \& Hospital, Mohri, Haryana, India 


\section{Results}

Table 1: Distribution of patients

\begin{tabular}{|c|c|c|}
\hline & Total- 78 & \\
\hline Gender & Boys & Girls \\
\hline Number & 48 & 40 \\
\hline
\end{tabular}

Table I shows that out of 78 patients, boys were 48 and girls were 40.

Table 2: Type of seizures in children

\begin{tabular}{|c|c|c|}
\hline Type & Number & P value \\
\hline Tonic clonic & 52 & \\
\hline Absence & 12 & \multirow{2}{*}{0.01} \\
\hline Myoclonic & 6 & \\
\cline { 1 - 2 } Focal with impaired consciousness & 4 & \\
\hline Unclassified & 4 & \\
\hline
\end{tabular}

Table II shows that common type of seizures was tonic clonic in 52, absence in 12 , myoclonic in 6 , focal with impaired consciousness in 4 and unclassified in 4 . The difference was significant $(P<0.05)$.

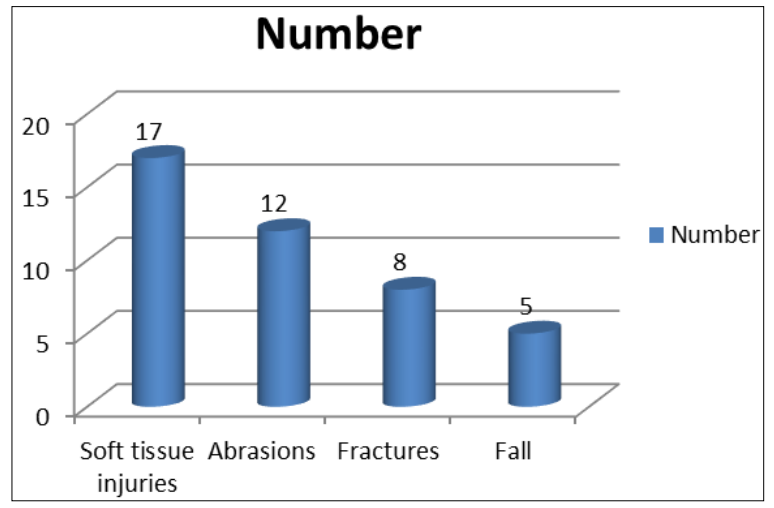

Graph I: Type of injuries in children

Graph I shows that common injuries were soft tissue injuries in 17, abrasions in 12, fractures in 8 and fall in 5. The difference was significant $(P<0.05)$.

\section{Discussion}

Epilepsy syndromes are classified mainly on the basis of their etiology and seizure manifestations. The individual seizure types are classified, and the diagnosis of each epilepsy syndrome is based on the seizure type(s) occurring in the syndrome and on its presumed etiology. Widely used classification systems were published in 1981 and 1989 and again just recently by the International League against Epilepsy ${ }^{[5]}$.

An epilepsy syndrome is called idiopathic if it is of genetic origin and the affected individuals are otherwise neurologically normal. An epilepsy syndrome is called symptomatic if it has a documented cause, and presumed symptomatic if an underlying cause seems probable but has not (yet) been definitively identified ${ }^{[6]}$. For correct and complete analysis and classification of signs and symptoms the principles of the neurological diagnosis should be followed: what? (Clinical diagnosis), where? (Topographical diagnosis), and why? (Etiological diagnosis) (4). A detailed history, complete general clinic and neurologic examination, diagnostic hypothesis and wise choice of complementary evaluations are all important elements for epilepsy diagnosis ${ }^{[7]}$. The present study was conducted to assess the cases of epilepsy in children.

In present study, out of 78 patients, boys were 48 and girls were 40 . We found that common type of seizures was tonic clonic in 52 , absence in 12 , myoclonic in 6 , focal with impaired consciousness in 4 and unclassified in 4 .

Prasad et al. ${ }^{[8]}$ found that a total of 272 children with epilepsy were screened, out of which 238 children met the inclusion criteria and were enrolled in the study. 243 siblings of cases were screened for inclusion. 30 cases and 31 controls were lost to follow up. A total of 420 children including 208 cases (62.5\% males) and 212 controls (51\% males) were finally analyzed. The mean (SD) age of cases was 9.4 (3.8) y and of controls was 9.0 (3.8) y. Among the cases, the most common seizure semiology was generalized (49\%). A past history of seizure-related injury was present in $3.3 \%$ of cases. 21 children with epilepsy (10\%) had injuries during the 12-month follow-up period. Among these 21 children, one child had 4 injuries, two had 2 injuries and the rest had a single injury (total 26 injuries). Nine (9/21, $42.9 \%$ ) of them had seizure related injuries and 14 out of 26 injuries were seizure related.

We found that common injuries were soft tissue injuries in 17 , abrasions in 12, fractures in 8 and fall in 5. Appleton et

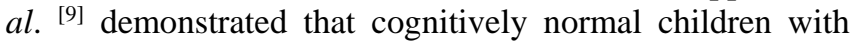
epilepsy did not have higher injury rates as compared to their nonepileptic peers. Children with epilepsy had a significantly higher risk for developing injuries (10\%) as compared to household controls $(4.7 \%)$.

Conclusion Authors found that common type of injuries in epileptic children were soft tissue and abrasions.

\section{References}

1. Wirrell EC. Epilepsy-related injuries. Epilepsia. 2006; 47:79-86.

2. Van den Broek M, Beghi E. RESt-1 Group. Accidents in patients with epilepsy: types, circumstances, and complications: A European cohort study. Epilepsia. 2004; 45:667-72.

3. Kwon C-S, Liu M, Quan H, Wiebe S, McChesney J, Wirrell $\mathrm{E}$ et al. The incidence of injuries in persons with and without epilepsy - a population-based study. Epilepsia. 2010; 51:2247-53.

4. Fisher RS, Van Emde Boas W, Blume W, Elger C, Genton P, Lee $\mathrm{P}$ et al. Epileptic seizures and epilepsy: definitions proposed by the International League against Epilepsy (ILAE) and the International Bureau for Epilepsy (IBE). Epilepsia. 2005; 46:470-2.

5. Gniatkowska-Nowakowska A. Fractures in epilepsy children. Seizure. 2010; 19:324-5.

6. Lawn ND, Bamlet WR, Radhakrishnan K, O’Brien PC, So EL. Injuries due to seizures in persons with epilepsy: a population-based study. Neurology. 2004; 63:156570.

7. Unglaub F, Woodruff S, Demir E, Pallua N. Patients with epilepsy: a high-risk population prone to severe burns as a consequence of seizures while showering. J Burn Care Rehabil. 2005; 26:526-528.

8. Prasad V, Kendrick D, Sayal K, Thomas SL, West J. Injury among children and young adults with epilepsy. Pediatrics. 2014; 133:827-35.

9. Appleton RE. Mersey Region Paediatric Epilepsy Interest Group. Seizure-related injuries in children with newly diagnosed and untreated epilepsy. Epilepsia. 2002; 43:764- 7 . 